\title{
RECOVERY OF ATRIAL FUNCTION AFTER COMBINED TREATMENT WITH SURGICAL REPAIR FOR ORGANIC HEART DISEASE AND MAZE PROCEDURE FOR ATRIAL FIBRILLATION
}

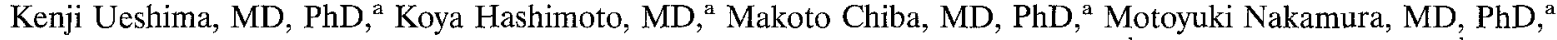 \\ Masataka Nasu, MD, PhD, ${ }^{a}$ Katsuhiko Hiramori, MD, PhD, ${ }^{a}$ Junya Kamata, MD, ${ }^{\mathrm{b}}$ Yoko Yagi, MD, PhD, \\ and Kohei Kawazoe, $\mathrm{MD}, \mathrm{PhD},{ }^{\mathrm{b}}$ Morioka, Japan
}

The maze procedure, a new surgical treatment for lone atrial fibrillation, was initially described by Cox and associates. ${ }^{1}$ Recently, combined treatment for organic heart disease and atrial fibrillation has been reported, but there have been few studies on atrial activity after combined treatment with surgical repair for organic heart disease and the maze procedure for atrial fibrillation. It is important to know how well atrial function recovers after combined surgical methods. Therefore we investigated the recovery of atrial function after the combined surgical treatment of organic heart disease and atrial fibrillation.

Methods. Twelve patients who received cardiac operation with a successful maze procedure were enrolled in this study. The patients consisted of four men and eight women, with a mean age of $60 \pm 11$ years. Organic heart diseases were mitral stenosis in two patients, mitral regurgitation in eight, and atrial septal defect in two. All patients underwent symptom-limited cardiopulmonary exercise testing with use of an upright bicycle ergometer with measurements of atrial natriuretic peptide (ANP) before and after exercise testing and Doppler echocardiography 1 week before the operation (control phase), 1 month after the operation (early phase), and 3 months after the operation (late phase).

Ventilatory threshold was determined in a standard manner by the $\mathrm{V}$-slope method. Peak velocities of the early filling (E) wave, atrial filling (A) wave, and $\mathrm{A} / \mathrm{E}$ ratio were determined by Doppler echocardiography. The timevelocity integrals of the $E(\mathrm{Ea})$ and $A(\mathrm{Aa})$ waves were then obtained by planimetry of the flow velocity profile. Left atrial active contractile fraction (LAACF) was expressed as the ratio of the atrial component during active atrial contraction $(\mathrm{Aa})$ to the total diastolic time velocity integral $(\mathrm{Ea}+\mathrm{Aa})$ and calculated as $\mathrm{LAACF}=\mathrm{Aa} /(\mathrm{Ea}+$ $\mathrm{Aa})$.

From the Second Department of Internal Medicine ${ }^{\mathrm{a}}$ and the Third Department of Surgery, ${ }^{b}$ Iwate Medical University, Morioka, Japan.

Received for publication March 6, 1996; accepted for publication May 6, 1996.

Address for reprints: Kenji Ueshima, The Second Department of Internal Medicine, Iwate Medical University, 19-1 Uchimaru, Morioka, Iwate, 020, Japan.

J Thorac Cardiovasc Surg 1997;113:214-5

Copyright (C) 1997 by Mosby-Year Book, Inc.

$0022-5223 / 97 \$ 5.00+0 \quad \mathbf{1 2 / 5 4 / 7 4 7 0 7}$
Results (Table I). Peak heart rate was $156 \pm 26$ beats/min before operation because of rapid ventricular response of atrial fibrillation. Although sinus rhythm was obtained in the early phase, peak heart rate was only $119 \pm 19$ beats $/ \mathrm{min}$. However, peak heart rate increased to $127 \pm 9$ beats/min in the late phase. Peak oxygen uptake and ventilatory threshold in the early phase increased significantly as compared with values in the control phase, and peak oxygen uptake showed a significant increase in the late phase.

ANP values at rest and after exercise testing in the control phase were $114 \pm 64$ and $172 \pm 74 \mathrm{pg} / \mathrm{ml}$, respectively. ANP values at rest and after exercise testing in the early phase decreased significantly and in the late phase demonstrated marked reduction. Percent increases of ANP levels after exercise in the control, early, and late phases were $62 \% \pm 58 \%, 36 \% \pm 32 \%$, and $128 \% \pm$ $103 \%$, respectively. In the late phase, percent increase of ANP levels after exercise revealed a significant augmentation.

After operation, A/E and LAACF values in the late phase significantly increased as compared with the values in the early phase.

Discussion. The attenuated heart rate response to exercise was obtained 1 month after operation. Because this

Table I. Changes in variables before and after surgical repair for heart disease and the maze procedure for atrial fibrillation

\begin{tabular}{|c|c|c|c|}
\hline & $\begin{array}{l}\text { Control } \\
\text { phase }\end{array}$ & Early phase & Late phase \\
\hline $\begin{array}{l}\text { Maximal heart rate } \\
\text { (beats/min) }\end{array}$ & $156 \pm 26$ & $119 \pm 19^{*}$ & $127 \pm 9^{*} \dagger$ \\
\hline $\begin{array}{l}\text { Anaerobic threshold } \\
(\mathrm{ml} / \mathrm{min} / \mathrm{kg})\end{array}$ & $12.1 \pm 1.8$ & $14.4 \pm 3.4 \ddagger$ & $15.1 \pm 1.8 \ddagger$ \\
\hline $\begin{array}{l}\text { Peak oxygen uptake } \\
(\mathrm{ml} / \mathrm{min} / \mathrm{kg})\end{array}$ & $17.1 \pm 3.1$ & $18.7 \pm 3.7 \ddagger$ & $20.6 \pm 3.6 \uparrow t$ \\
\hline $\begin{array}{l}\text { ANP level at rest } \\
(\mathrm{pg} / \mathrm{ml})\end{array}$ & $114 \pm 64$ & $43 \pm 21 \div$ & $22 \pm 15^{*} \dagger$ \\
\hline $\begin{array}{l}\text { ANP level after exercise } \\
(\mathrm{pg} / \mathrm{ml})\end{array}$ & $172 \pm 74$ & $62 \pm 42 \doteqdot$ & $47 \pm 35+\frac{1}{\dot{*}}$ \\
\hline $\begin{array}{l}\text { Percent increase of ANP } \\
\text { after exercise }(\%)\end{array}$ & $62 \pm 58$ & $36 \pm 32$ & $128 \pm 103 \dagger$ \\
\hline $\mathrm{A} / \mathrm{E}$ & - & $0.24 \pm 0.19$ & $0.39 \pm 0.18 \dagger$ \\
\hline LAACF & - & $0.11 \pm 0.06$ & $0.21 \pm 0.04 \S$ \\
\hline
\end{tabular}


Volume 113, Number 1

heart rate response can be similar to that of the transplanted heart, ${ }^{2}$ the attenuated heart rate response to exercise early after the maze procedure may be caused by denervation of the sinoatrial node as a result of multiple incisions in the atrial wall. If the attenuated heart rate response to exercise early after the maze procedure was caused by denervation of the sinoatrial node, recovery of the heart rate response late after operation can be explained by the time course of reinnervation of the sinoatrial node. ${ }^{3}$

ANPs have been extracted from atrial myocytes of mammals, including human beings, and play an important role in natriuresis and vasodilation. Because ANP was excreted markedly after exercise, the determination of plasma ANP level after exercise allows evaluation of the atrial function as the excretion ability. Percent increase of ANP after exercise was higher in the late phase than that in the control and early phases, which suggests that atrial function of ANP excretion was restored over time.

Transient atrial dysfunction occurred in patients with atrial fibrillation who underwent electrical cardioversion, and mechanical atrial function is reduced when conversion is achieved after atrial fibrillation has been sustained for more than a week. ${ }^{4}$ The mechanism of atrial dysfunction after elimination of atrial fibrillation is unknown. Shapiro and colleagues ${ }^{4}$ postulated that postischemic stunned atrial myocardium, as in the occurrence of ischemia during ventricular fibrillation, may explain this phenomenon.
The delayed recovery of atrial function may influence the improved exercise capacity in the late phase after combined treatment consisting of surgical repair for organic heart disease and atrial fibrillation.

We conclude that transient attenuation of atrial function, seen as sinoatrial node response, excretion of ANP, and mechanical contractility, occurred in patients after combined treatment with surgical repair for heart disease and the maze procedure for atrial fibrillation. The late recovery of atrial function may improve exercise capacity over time.

\section{REFERENCES}

1. Cox JL, Schuessler RB, D'Agostino HJ, et al. The surgical treatment of atrial fibrillation: III-development of a definitive surgical procedure. J Thorac Cardiovasc Surg 1991;101: $569-83$.

2. Ehrman J, Keteyian S, Fedel F, Rhodas K, Levine TB, Shepard R. Cardiovascular responses of heart transplant recipients to graded exercise testing. J Appl Physiol 1992;73: $153-66$.

3. Peiss CN, Cooper T, William VL, Randall WC. Circulatory responses to electrical and reflex activation of the nervous system after cardiac denervation. Circ Res 1966;19:153-66.

4. Shapiro EP, Effron MB, Lima S, Ouyang P, Siu CO, Bush D. Transient atrial dysfunction after conversion of chronic atrial fibrillation to sinus thythm. Am J Cardiol 1989;13:617-23.

\title{
CEREBRAL EMBOLIZATION IS REDUCED WITH USE OF THE STAB TECHNIQUE FOR AORTIC CANNULATION COMPARED WITH THE SIDE-CLAMP TECHNIQUE
}

\author{
Uday Trivedi, FRCS, Christopher Davies, BSc, James Roxburgh, MS, FRCS(C/Th), and \\ Graham Cooper, MD, FRCSEd(C/Th), London, United Kingdom
}

Manipulation of the heart and ascending aorta during cardiac operations is an important cause of cerebral emboli. ${ }^{1,2}$ To date there has been no reported study on the influence of aortic cannulation technique and the prevalence of cerebral microemboli. We compared the production of emboli, measured in the left middle cerebral artery with transcranial Doppler imaging between the side-clamp technique of aortic cannulation and the stab technique. Both techniques involve trauma to the aortic wall and the possibility of releasing atheromatous debris

From the Department of Cardiothoracic Surgery, St. Thomas' Hospital, London, United Kingdom.

Received for publication Jan. 10, 1996; accepted for publication June 20, 1996.

Address for reprints: U. H. Trivedi, FRCS, Department of Cardiothoracic Surgery, St. Thomas' Hospital, Lambeth Palace Road, London, SE1-7EH, England.

J Thorac Cardiovasc Surg 1997;113:215-6

Copyright (C) 1997 by Mosby-Year Book, Inc.

$0022-5223 / 97 \$ 5.00+0 \quad \mathbf{1 2 / 5 4 / 7 6 0 4 7}$ and of allowing air to enter during the introduction of the cannula. Transcranial Doppler ultrasonography is unable to differentiate gaseous from particulate emboli accurately, but it is a useful method to measure the total number of emboli that reach the brain. Because the middle cerebral artery supplies $80 \%$ of the ipsilateral cerebral hemisphere, measurement of emboli within this vessel will reffect the total embolic load for each hemisphere.

Patients and methods. Twenty patients undergoing elective cardiac operations were prospectively randomized to either the stab (group S) or side-clamp (group C) technique of aortic cannulation. Cannulation was done by one of two senior surgeons (J. R. and G. C.) in equal numbers with each technique, and both surgeons were equally conversant with both techniques. All patients were undergoing first-time elective operation, and those with cerebrovascular disease were excluded.

The two cannulation techniques are similar, but in the stab technique a transverse incision is made in the aorta with a scalpel and as the scalpel is withdrawn the aortic cannula is introduced through the incision. In the sideclamp technique, a Cooley side-biting clamp is used to 